مطالعه اثر ضدباكتريايى عصارههاى آبى زيتون، تاجريزى سياه، كليوره، درمنه و شيرينبيان بر برخى باكترىهاى بيماريزاى منتقله از غذا

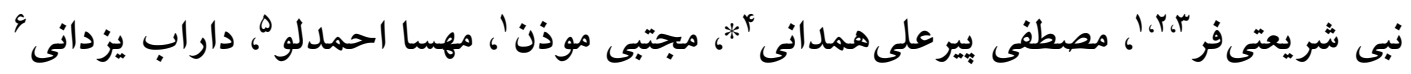

$$
\begin{aligned}
& \text { 1- كروه مهندسى بهداشت محيط، دانشكده بهداشت، دانشكاه علوم يزشكى تهر ان، تهران، ايران }
\end{aligned}
$$

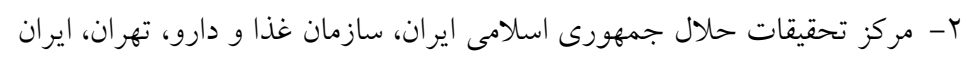

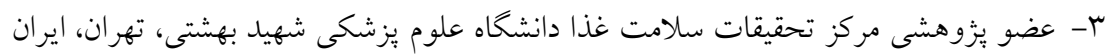

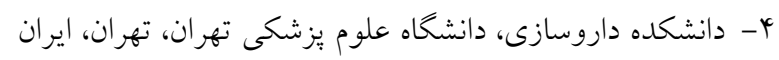

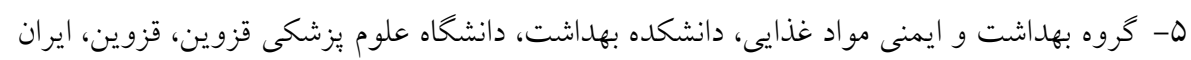

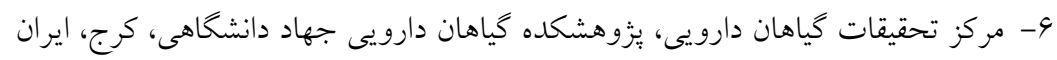

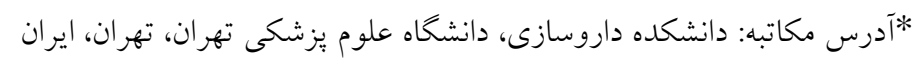

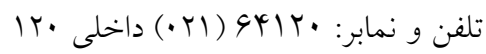

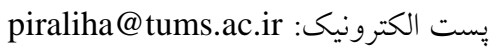

مقدمه: در دههاى اخير تمايل به استفاده از نگهدارندههاى طبيعى با توجه به نخر انى جامعه از نخهدارندههاى شيميايى رو به افزايش است.

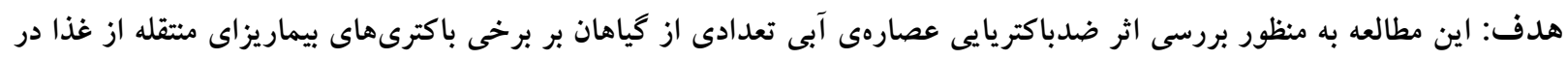

$$
\text { محيط آزمايشخاهى انجام شده است. }
$$

روش بررسى: در اين مطالعه، گياهان مورد بررسى از سطح بازار شهر تهران تهيه و عصاره آبى آنها استخراج شد. غلظتهاى

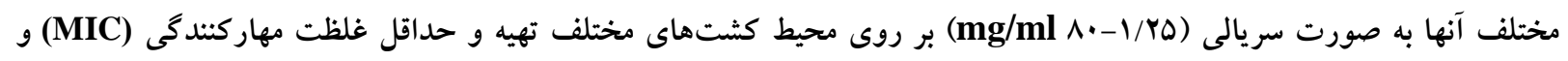

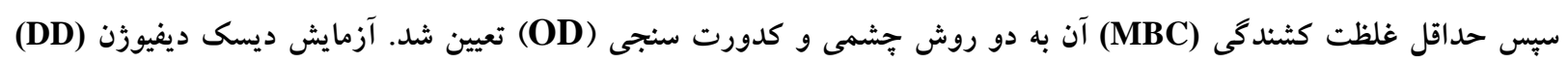

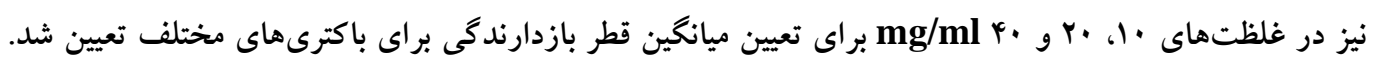

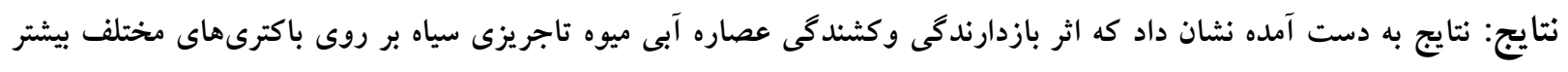

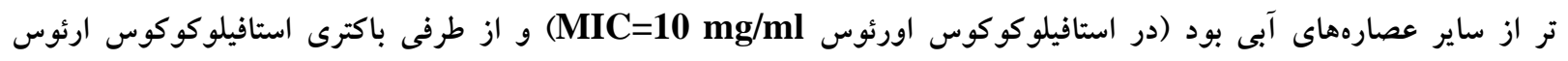

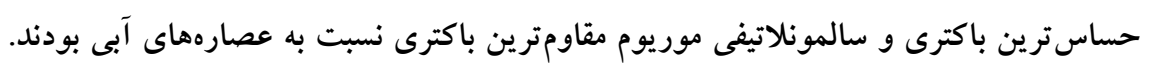

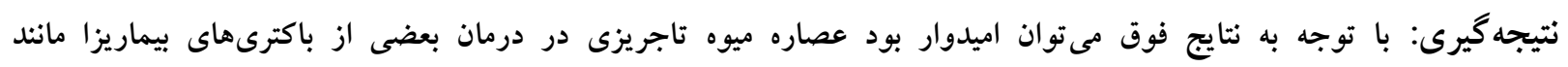

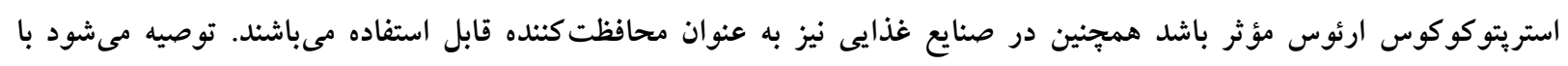

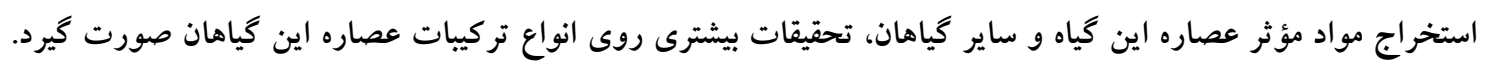
كلوازگحان: اثر ضد باكتريايى، بيمارىهاى منتقله از غذا، حداقل غلظت بازدارندگى و كشندگى، عصاره آبى 


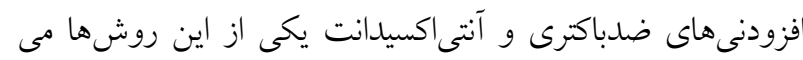

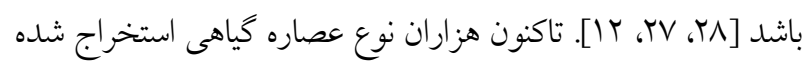

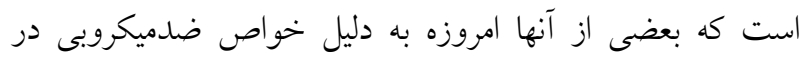

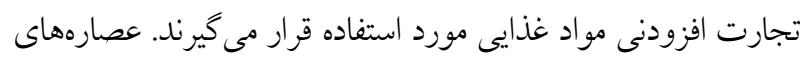

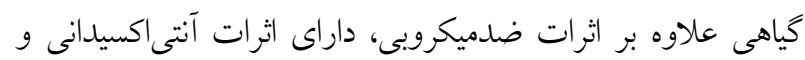

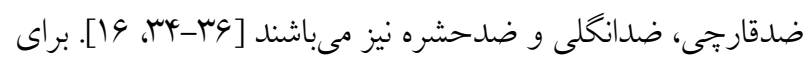

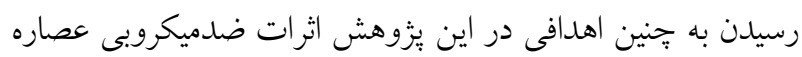

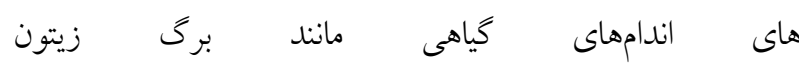
تاح نداره هرباريومى (Olea europaea L.) تاجريزى (Solanum americanum Mill.) با شماره

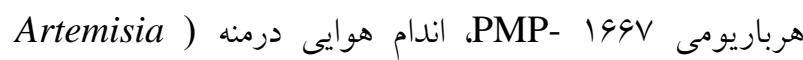
(sieberi Besser PMP- با شماره هرباريومى (Teucrium polium L.) و ريشه شيرينبيان (Glycyrrhiza glabra L.) با شماره هرباريومى PMP-YVY مورد ارزيابى قرار كرفتهاند. تاجريزى

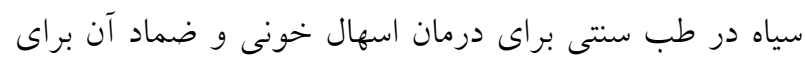

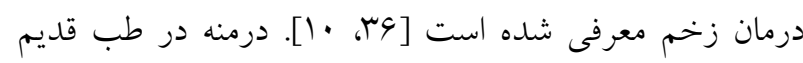

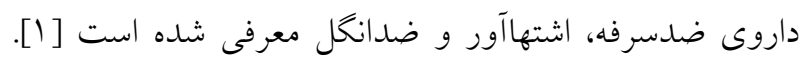

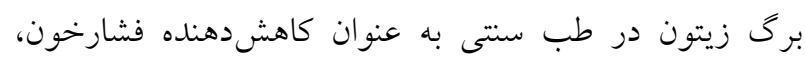

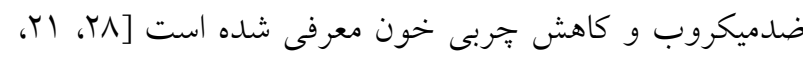

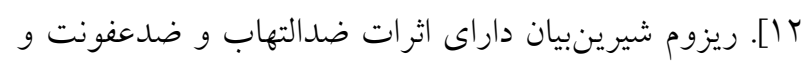

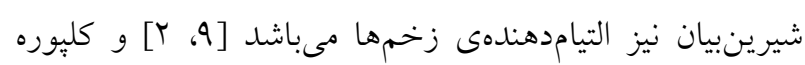

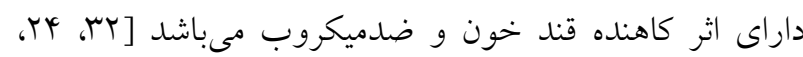

. $[11$

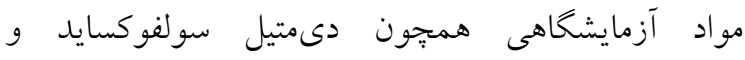

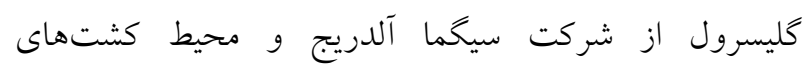

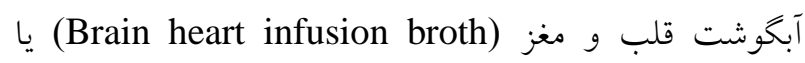

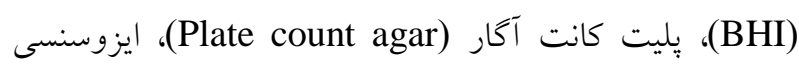

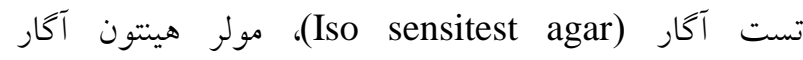

امروزه بحث ايمنى مواد غذايى، از مهمترين مباحث روز

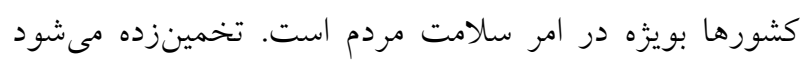

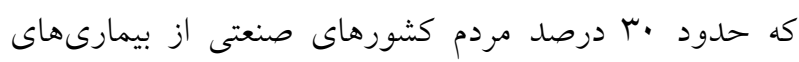

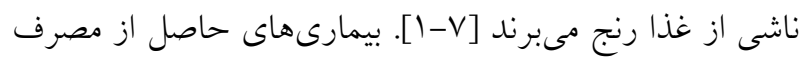

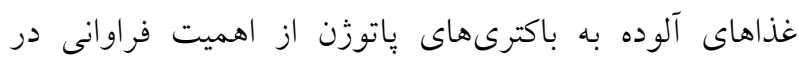

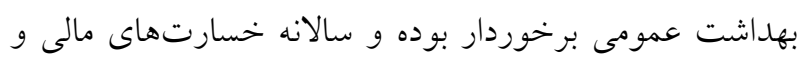

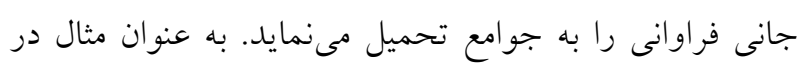

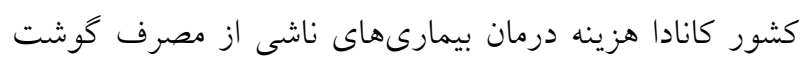

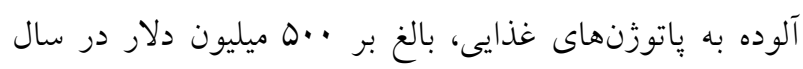

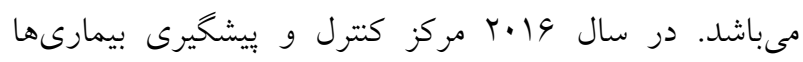

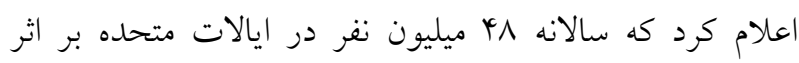

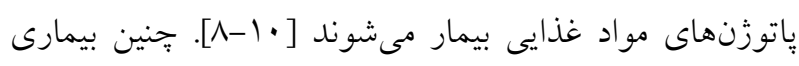

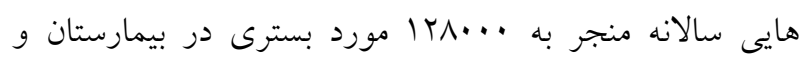

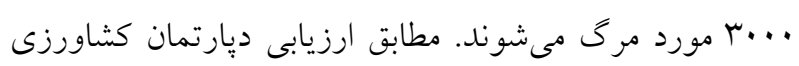

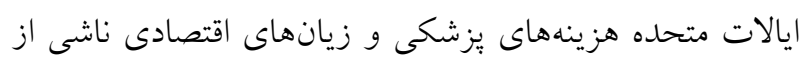

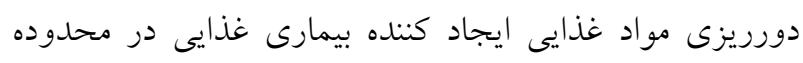

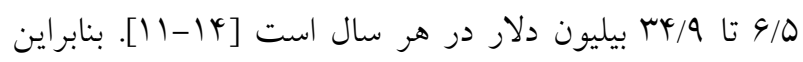

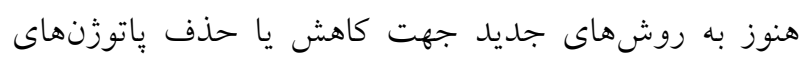

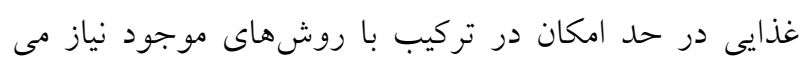

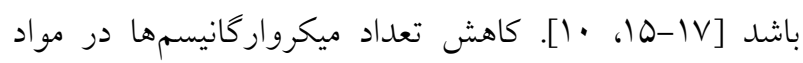

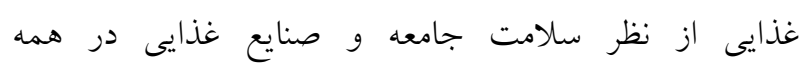

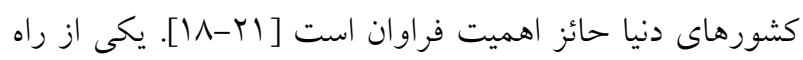

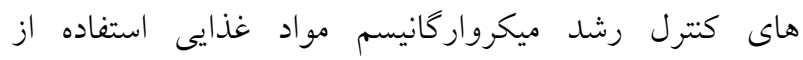

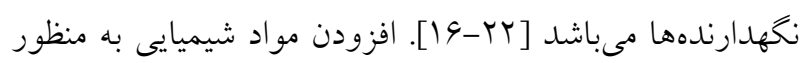

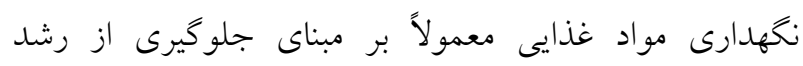

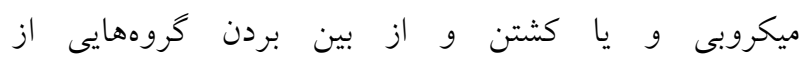

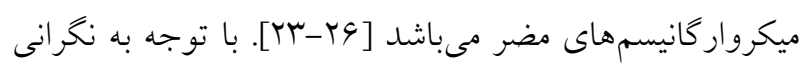

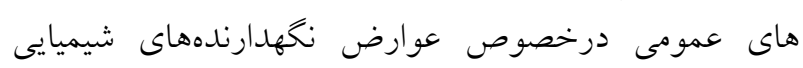

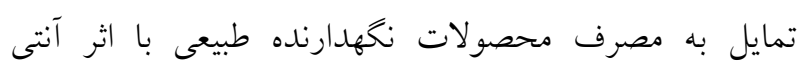

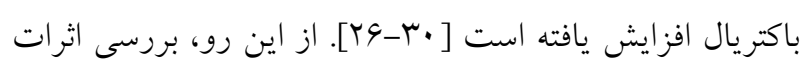

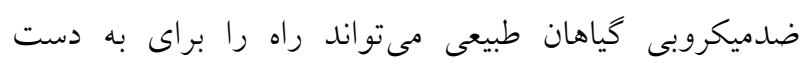

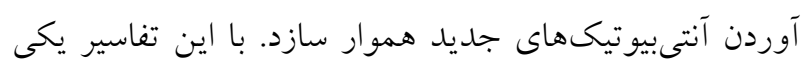

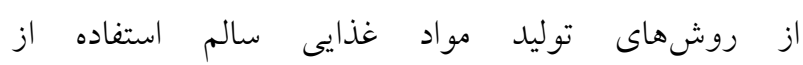


ساعت و دو مرتبه به طور متوالى تجديد كشت شد. در مرحله

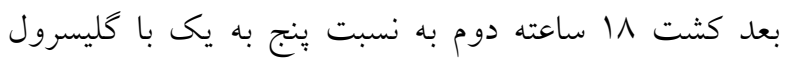

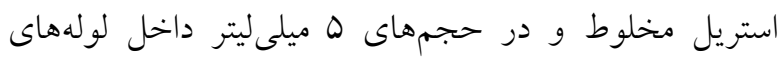

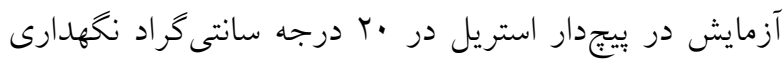
شد تا در طول مطالعه مورد استفاده قرار گيرد.

$$
\text { تهيه ميزان تلقيح باكترى }
$$

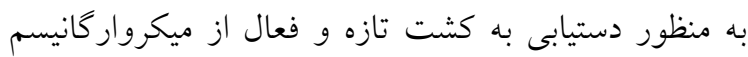

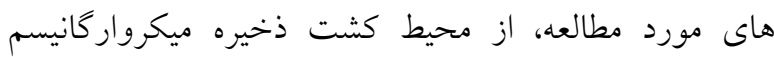

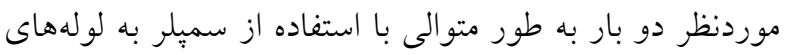

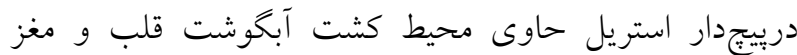

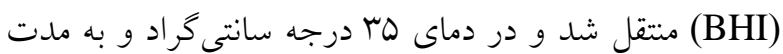

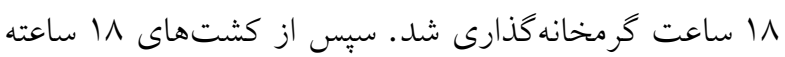

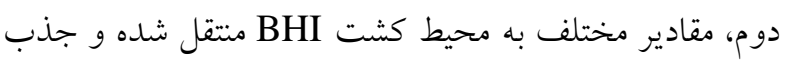

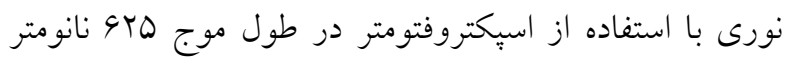
تعيين شد و سوسيانسيون باكترى، معادل نيم مك فارلند تهيه شد (غلظت ميكروبى، معادل

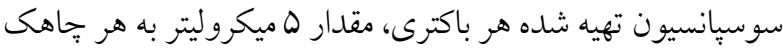

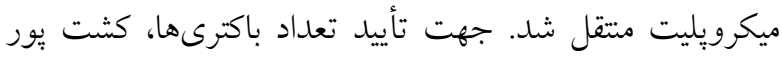

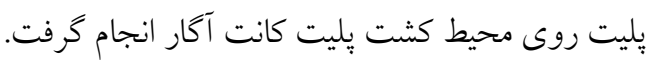

تهيه رقتهاى سريالى از عصارهها و تعيين حداقل بازدارندگى (Minimum Inhibitory Concentration) MIC براث ميكرودايلوشن

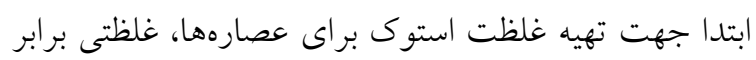

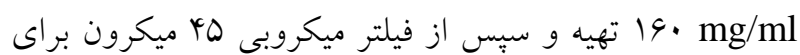
استريل نمودن عبور داده شد. غلظتهاى سريالى براى عصاره

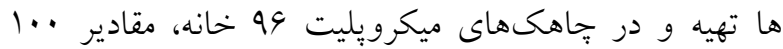
ميكروليتر از هر يكى از غلظتهاى عصاره تهيه شده، 90

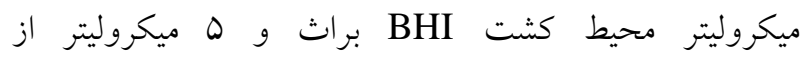

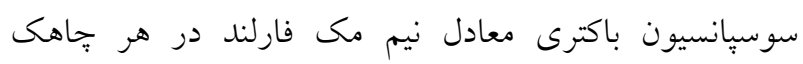

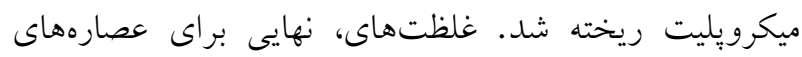

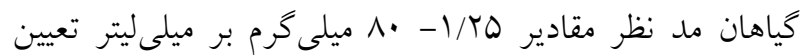

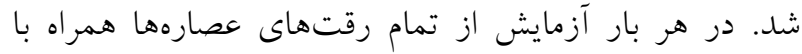

(Mueller hinton agar)

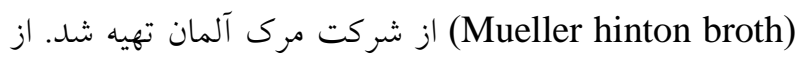
تجهيزات آزمايشگاهى شامل سميلر (إندورف آلمان)،

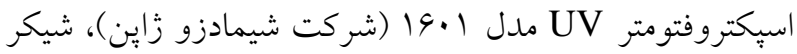
(شركت IKA آلمان)، انكوباتور (Memert آلمان) استفاده شد.

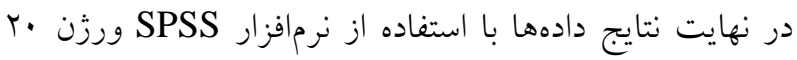
مورد آناليز آمارى قرار كرفتند. جمع آورى گياهان و تهيه عصاره در اين مطالعه تجربى آزمايشخاهى ابتدا كَاهان مورد نظر از

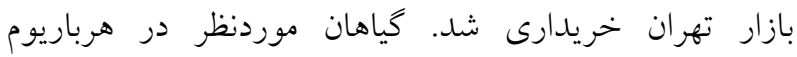

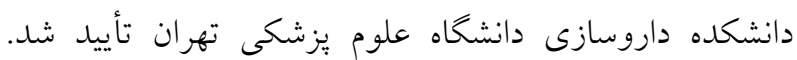

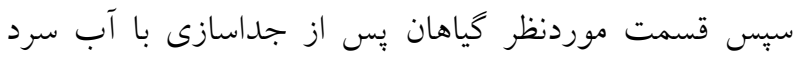

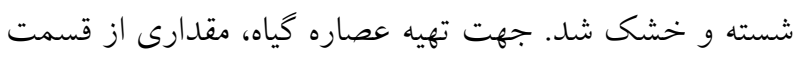

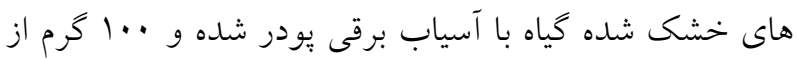

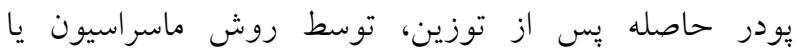

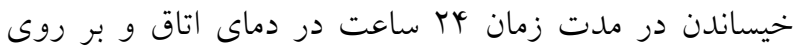
شيكر با سرعت •ror دور در دقيقه عصارهكيرى انجام شد.

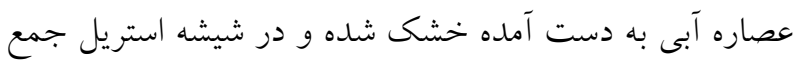

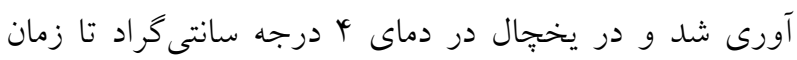

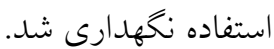
سويههاى باكترى و غنى سازى ميكروار كانيسم باكترى سالمونلا تايفى موريوم (Salmonella Typhimurium)

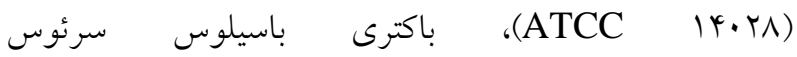
(ATCC IIVVA) (Bacillus cereus) (ATCC roqrr) (Escherichia coli:)

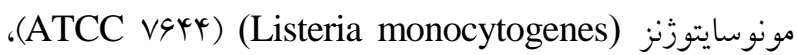
باكترى استافيلوكوكوس اورئوس (Staphylococcus aureus)

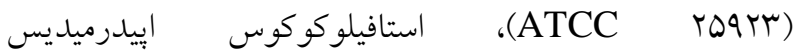
و (ATCC I YYYA) (Staphylococcus epidermidis)

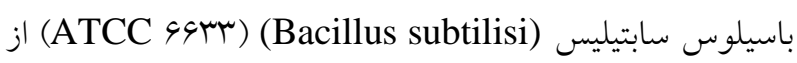
مؤسسه رازى تهيه شد. كشت ليوفيليزه هر باكترى در محيط

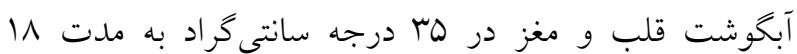


افزارSPSS Version16 انجام شد. جهت بررسى وجود اختلاف

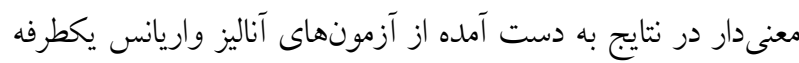

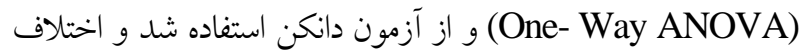

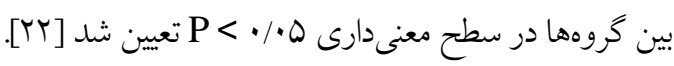

\section{نتايج}

r. بررسى با نشان داد عصارمى برى زيتون در غلظت

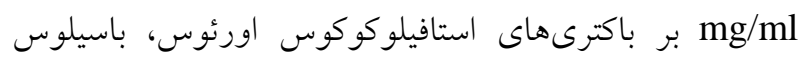

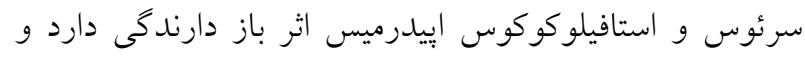

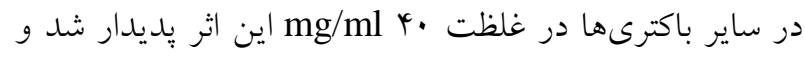

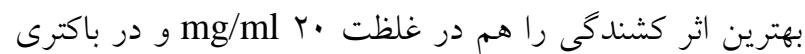

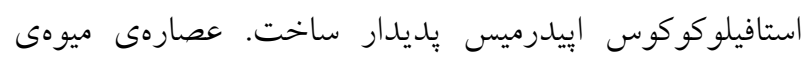

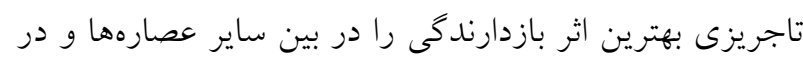

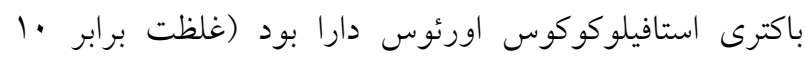

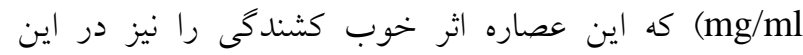

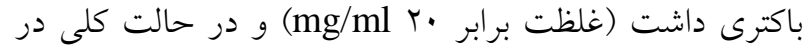

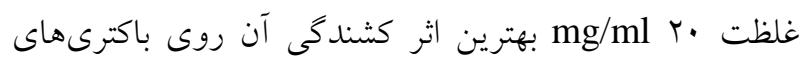

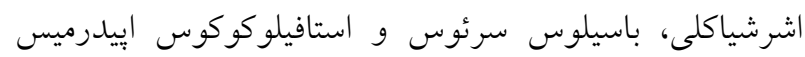

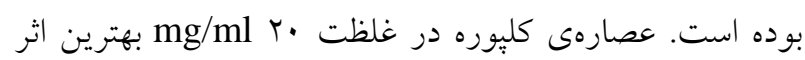

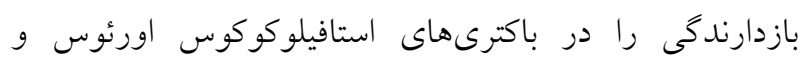

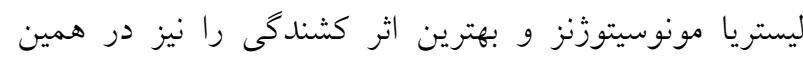
غلظت بر باكترى استافيلوكوكوس اورئوس داشت. عضر عصاره

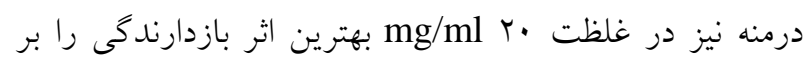

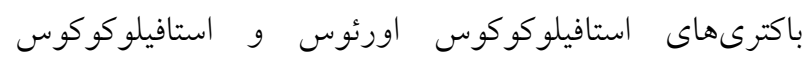

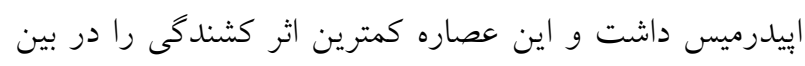

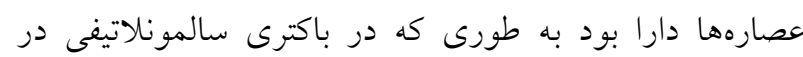

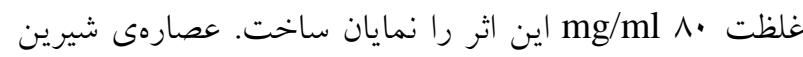

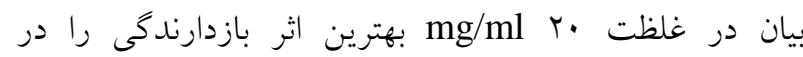
استافيلوكوكوس اورئوس، اشرشياكلى و باسيلوس سرئوس دارا

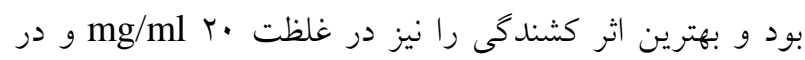
باكترى باسيلوس سرئوس نشان داد (جدول شماره (1). بر طبق جدول شماره Y نتايج نشان دادند بيشترين ميانخين قطر هاله بازدارندگى (كه نشان از بيشترين اثر كشندكى است) مربوط به عصاره ميوه تاجريزى سياه مىشود و حساسترين
محيط كشت بدون تلقيح باكترى به عنوان شاهد در يكى رديف

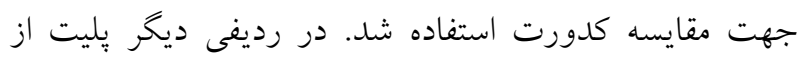

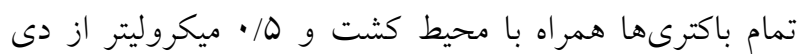

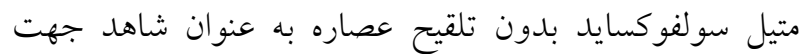

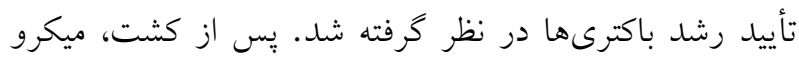

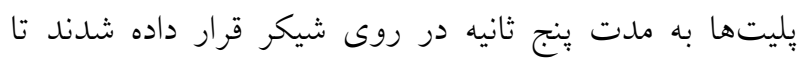

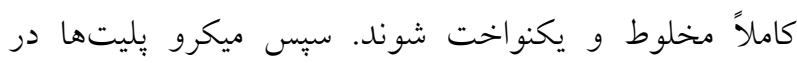

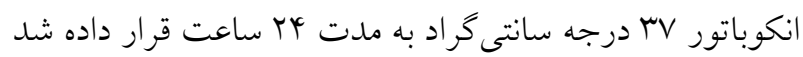

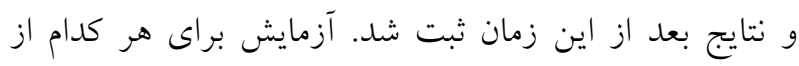

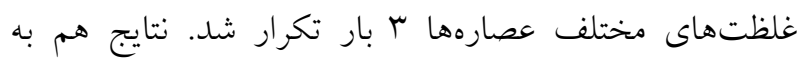
صورت جشمى (كيفى) و هم optical dencity) OD

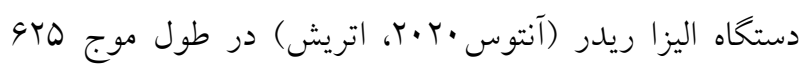

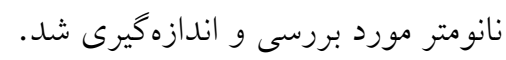

\section{نعيين حداقل غلظت كثندگى Minimum MBC)}

\section{Bactericidal concentration)} براى تعيين MBC مقدار ·ل ميكروليتر از هر يك از ميكرو

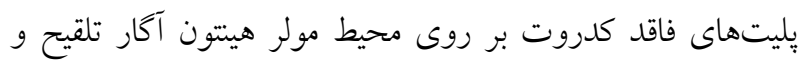

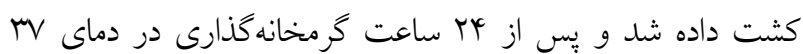

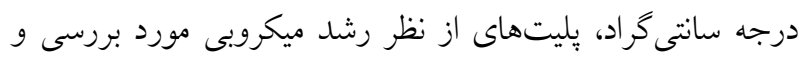

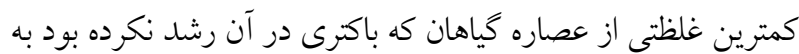
عنوان غلظت كشندكى MBC كزارش كرديم [19، 10]. آزمايش ديسك ديفيوزن (DD)

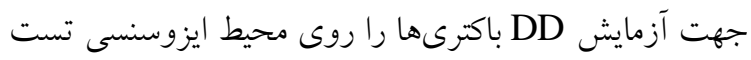

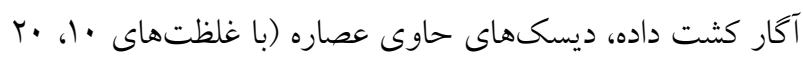

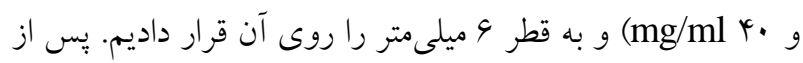

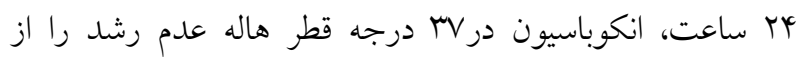

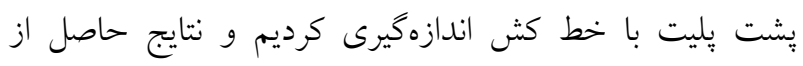

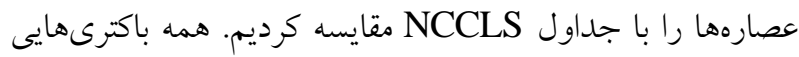

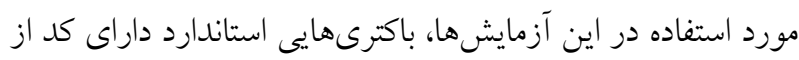
ATCC

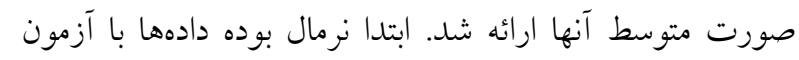

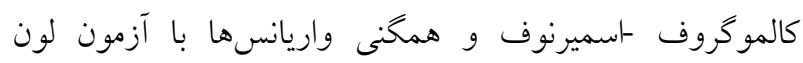

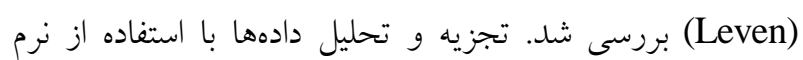


تفاوت معنىدارى بين انواع باكترىهاى مورد استفاده در بررسى متوسط قطر هاله عدم رشد اطراف ديسك عصارههاى

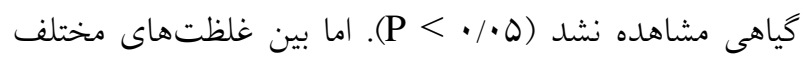
كليه عصارههاى آبى (به جز در عصاره آبى برگ زيتون) و تأثير آن بر متوسط قطر هاله عدم رشد اطراف ديسك عصارههاى

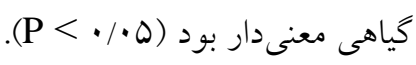

باكترى به آن نيز استريتوكوكوس ارئوس بوده است كه اين دادهاى آزمونهاى MIC و MBC را تأييد مىنمايد و همجينين با افزايش غلظت عصارهها ميزان ميانخين قطر هاله افزايش يافته است. كمترين ميانخين قطر هالهى بازدارندگى مربوط به عصارهى برى زيتون با غلظت · ماده است كه نشان از كمترين

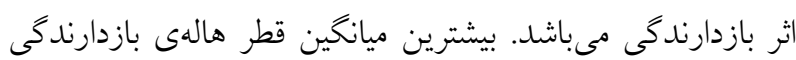
نيز همانطور كه اشاره شد مربوط به عصارهى ميوهى تاجريزى و در غلظت . mg/ml ب بوده است.

جدول شماره ا - تعيين متوسط (rn) غلظت MIC و MBC عصاره گياهان برگ زيتون، ميوه تاجريزى سياه، كلبوره، درمنه و شيرينبيان بر باكترى هاى استافيلوكوكوس ارئوس، سالمونلا تيفى موريوم، اشرشيا كلى، باسيلوس سرئوس، باسيلوس سابتيليس، ليستريا مونسايتوزنز و استافيلوكوكوس إييدرميس (ميلى

\begin{tabular}{|c|c|c|c|c|c|c|c|c|c|c|c|c|c|c|}
\hline \multicolumn{2}{|c|}{ 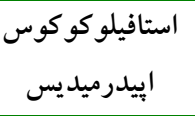 } & \multicolumn{2}{|c|}{ مونسيتورزنز } & \multicolumn{2}{|c|}{ باسيلوس } & \multicolumn{2}{|c|}{ باسيلوس } & \multicolumn{2}{|c|}{ اشرشياكولى } & \multicolumn{2}{|c|}{ سالمونلا تيفى } & \multicolumn{2}{|c|}{ استافيلو كوكوس } & \multirow{2}{*}{ باكترى } \\
\hline $\mathrm{MBC}$ & MIC & $\mathrm{MBC}$ & MIC & $\mathrm{MBC}$ & MIC & $\mathrm{MBC}$ & MIC & MBC & MIC & MBC & MIC & MBC & MIC & \\
\hline r. & $r \cdot$ & k. & c. & k. & k. & k. & $r$ r. & k. & r. & k. & r. & k. & r. & برى زيتون \\
\hline r. & $r \cdot$ & 4. & 4. & r. & r. & 4. & $r \cdot$ & $r \cdot$ & $r \cdot$ & 4. & k. & r. & 1. & ميوه تاجريزى سياه \\
\hline k. & c. & r. & c. & k. & k. & k. & $\varphi$. & c. & k. & k. & 4. & r. & r. & كليوره \\
\hline r. & r. & r. & r. & r. & r. & r. & r. & r. & r. & $\wedge$. & r. & r. & $r \cdot$ & 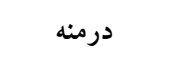 \\
\hline r. & r. & r. & r. & r. & r. & r. & r. & r. & r. & r. & r. & r. & $r \cdot$ & شيرين بيان \\
\hline
\end{tabular}

جدول شماره Y - متوسط (rn=) قطر هاله عدم رشد اطراف ديسك عصارههاى گياهى (برحسب ميلىمتر) در كشت باكترىهاى استافيلوكوكوس ارئوس،

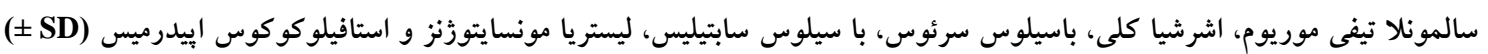

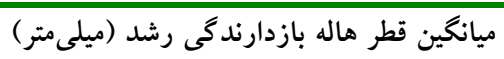

\begin{tabular}{|c|c|c|c|c|c|c|}
\hline شيرين بيان & عصاره درمنه & عصاره كليوره & عصاره تاجريزى سياه & عصاره برى زيتون & غلظت & باكترى \\
\hline $\mid r / \mu \pm \cdot / r \Lambda^{a}$ & $1 Y / 9 \pm \cdot / 0 r^{a}$ & $11 / \tilde{\mu} \pm \cdot / 4 r^{a}$ & $1 \% / 9 \pm \cdot / \mu \varphi^{a}$ & $1 \cdot / 9 \pm \cdot / \mu^{a}$ & 1. & \\
\hline $1 \Lambda \pm \cdot / 4 y b$ & $\mid r / \Delta \pm \cdot / r \Delta b c$ & $\mid r / r \pm \cdot / r \psi^{b}$ & $19 / \pi \pm \cdot / 4 \Delta^{b}$ & $10 \pm \cdot / 0^{a}$ & $r \cdot$ & استافيلوكوكوس ارئوس \\
\hline$I V / V \pm \cdot / \Gamma \omega^{b}$ & $\mid \vee \pm \cdot / \Psi^{4} \Lambda^{c}$ & $14 \pm \cdot / \mu q b$ & $19 / 4 \pm \cdot / \mu^{c}$ & $\mid V / 9 \pm \cdot / 4 \Delta^{a}$ & k. & \\
\hline $11 / 4 \pm \cdot / 4 \mu^{a}$ & $1 \cdot \pm \cdot \mu_{c} \mathrm{a}$ & $1 \cdot / \mu \pm \cdot / 1 \wedge^{a}$ & $14 / 9 \pm \cdot / 0^{a}$ & $1 \cdot / r \pm \cdot / 4 r^{a}$ & 1. & \\
\hline $\mid r / \Gamma \pm \cdot / 1 \Lambda^{b}$ & $11 / \wedge \pm \cdot / 4 r^{b c}$ & $1 \cdot \pm \cdot / \wedge^{\mathrm{b}}$ & $10 / 4 \pm \cdot / 4 \theta^{b}$ & $|V /| \pm \cdot \pi \omega^{a}$ & r. & سالمونلا تيفى موريوم \\
\hline $19 \pm \cdot / T \Lambda^{b}$ & $11 / Q \pm \cdot / 4 Y^{c}$ & $1 \cdot / \Delta \pm \cdot / \mu^{b}$ & $\mid \psi / q \pm \cdot / \mu^{c}$ & $1 \cdot / \Lambda \pm \cdot / \mu \varphi^{a}$ & r. & \\
\hline $\mid r / \mu \pm \cdot / 4 \psi^{a}$ & $q / V \pm \cdot /^{\mathrm{a}}$ & $1 \cdot / \wedge \pm \cdot / 4 \Delta^{a}$ & $10 / \mu \pm \cdot / \mu^{\prime} a$ & $11 / r \pm \cdot / 4 r^{a}$ & 1. & \\
\hline $\mid \psi / \Lambda \pm \cdot / \mu^{b}$ & $\mid r / T \pm \cdot / T \Lambda^{b c}$ & $11 / \Delta \pm \cdot / \mu^{b}$ & $19 / \mathrm{N} \pm \cdot / 1 \Lambda^{\mathrm{b}}$ & $I T / Q \pm \cdot / \Delta Y^{a}$ & r. & ا شريشيا كولى \\
\hline $1 \omega / V \pm \cdot \pi \omega^{b}$ & $1 r \pm \cdot / 0^{c}$ & $\mid r / T \pm \cdot / 4 T^{b}$ & $19 / r \pm \cdot / \pi V^{c}$ & $\mid r / \mu^{\mu} \pm \cdot / \mu^{\mathrm{a}}$ & k. & \\
\hline$I T / V \pm \cdot / D^{a}$ & $1 \cdot / 1 \pm \cdot / 4^{\mathrm{a}}$ & $9 / 9 \pm \cdot / / \mathrm{ra}^{\mathrm{a}}$ & $\mid r / \Delta \pm \cdot / \mu^{a}$ & $1 \cdot / r \pm \cdot / 4 r^{a}$ & 1. & \\
\hline $10 / 4 \pm \cdot / \mu^{b}$ & $11 / N \pm \cdot / 0^{b c}$ & $\mid r / T^{\mathcal{A}} \pm \cdot / T \Lambda^{\mathrm{b}}$ & $19 / r \pm \cdot / 0 r^{b}$ & $11 / 0 \pm \cdot \pi c a$ & r. & باسيلوس سرئوس \\
\hline $19 / 0 \pm \cdot \pi 4 \mathrm{~b}$ & $19 \pm \cdot / 0 r^{c}$ & $\mid r / V \pm \cdot / \Lambda^{\mathrm{b}}$ & $\mid N / \Lambda \pm \cdot / r \Delta^{c}$ & $1 \cdot / v \pm \cdot / 1 \wedge^{a}$ & $r$. & \\
\hline
\end{tabular}




\begin{tabular}{|c|c|c|c|c|c|c|}
\hline \multicolumn{7}{|c|}{ ميانگين قطر هاله بازدارندگى رشد (ميلىمتر) } \\
\hline شير بين بيان & عصاره درمنه & عصاره كليوره & عصاره تاجريزى سياه & عصاره برى زيتون & 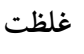 & باكترى \\
\hline $11 / \wedge \pm \cdot / 1 \wedge^{a}$ & $q / \Lambda \pm \cdot / 4 r^{a}$ & $1 \cdot / r \pm \cdot / 4 \Delta^{a}$ & $19 / \Gamma \pm \cdot / r \omega^{a}$ & $I T / V \pm \cdot / \mu^{\mathrm{a}}$ & 1. & \\
\hline $10 \pm \cdot / \mu^{b}$ & $11 / 1 \pm \cdot / T \wedge$ bc & $1 r \pm \cdot / \mu^{b}$ & $\left|N / \Psi^{\leftarrow} \pm \cdot / 4\right|^{b}$ & $\mid r \pm \cdot / r \Lambda^{a}$ & r. & باسيلوس سابتيليس \\
\hline$|V /| \pm \cdot / \mu^{b}$ & $11 / 9 \pm \cdot / \pi 4 \mathrm{c}$ & $\mid r / \mu \pm \cdot / \mu q^{b}$ & $19 / 1 \pm \cdot / 11^{c}$ & $\mid r / \Lambda \pm \cdot / 10^{a}$ & c. & \\
\hline $1 T / \Delta \pm \cdot / \Delta^{a}$ & $1 \cdot / V \pm \cdot / 1 \Lambda^{a}$ & $1 \cdot / 1 \pm \cdot / r \Lambda^{a}$ & $19 / 4 \pm \cdot / 4 V^{a}$ & $1 \cdot / \Lambda \pm \cdot / \Delta r^{a}$ & 1. & \\
\hline $\mid r / \Lambda \pm \cdot / \mu^{b}$ & $11 / 4 \pm \cdot / \mu y b c$ & $11 / \wedge \pm \cdot / 1 \wedge^{b}$ & $11 / 9 \pm \cdot / \mu^{b}$ & $11 \pm \cdot / 4 \Psi^{a}$ & $r \cdot$ & ليستريا مونوسيتوزنز \\
\hline $\mid r / \mu \pm \cdot / \mu r^{b}$ & $11 \pm \cdot / \mu^{c}$ & $11 / 0 \pm \cdot / \pi c^{b}$ & $\mid \Lambda / \vee \pm \cdot / \Lambda \Lambda^{c}$ & $1 \cdot / 9 \pm \cdot / T \Delta^{a}$ & r. & \\
\hline $\mid r / r \pm \cdot / r q a$ & $q / \wedge \pm \cdot / 0 r^{a}$ & $Q / \Lambda \pm \cdot / \Gamma \Delta^{a}$ & $1 Q / \Lambda \pm \cdot / 4 r^{a}$ & $9 / \Gamma \pm \cdot / 1 \wedge^{a}$ & 1. & \\
\hline $10 / \Lambda \pm \cdot / 4 Y^{b}$ & $\mid r / \Delta \pm \cdot / T \Lambda^{b c}$ & $11 / V \pm \cdot / \mu^{b}$ & $1 \Lambda / \mu \pm \cdot / \mu^{b}$ & $1 \cdot / 1 \pm \cdot / 19^{a}$ & r. & استافيلوكوكوس إيدرميديس \\
\hline$I V / V \pm \cdot / / \Lambda^{b}$ & $|r /| \pm \cdot / \pi \Delta^{c}$ & $\mid r / Q \pm \cdot / \Delta r^{b}$ & /N/9 & $11 / 0 \pm \cdot / \mu^{a}$ & r. & \\
\hline
\end{tabular}

*حروف مشابه در يك رديف نشان دهنده عدم وجود تفاوت معنى دار بودن در سطح Q•/ > P است.

كه اين عصارهها اثر قويى بر اين ميكرو ارگانيسم دارند [ [آ]].

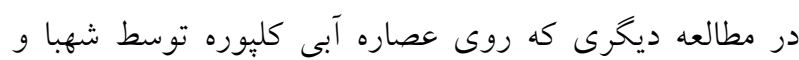

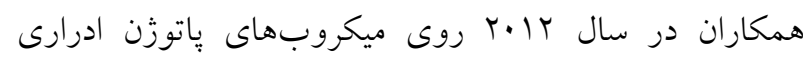

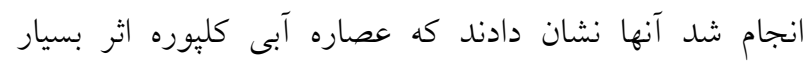

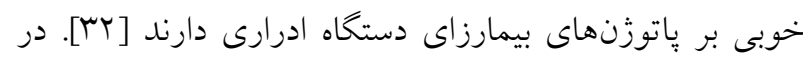

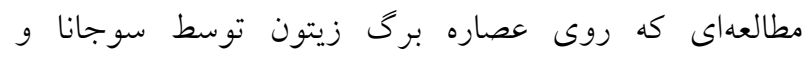

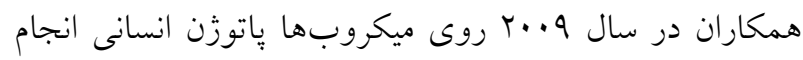

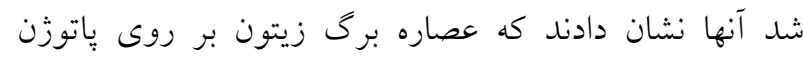

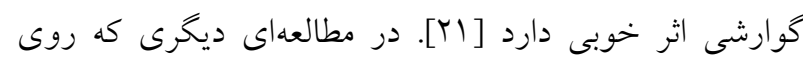

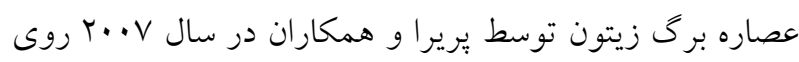

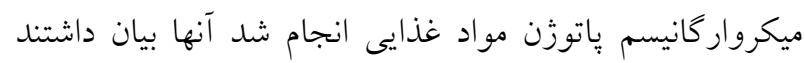

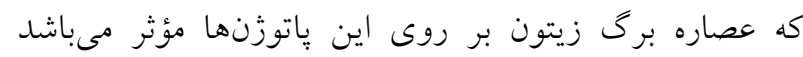

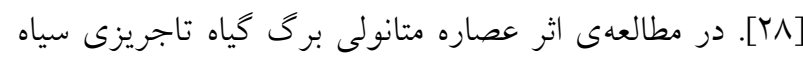

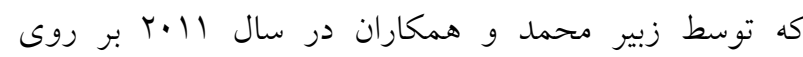

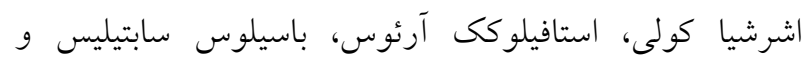

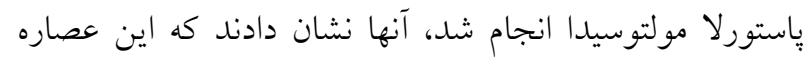

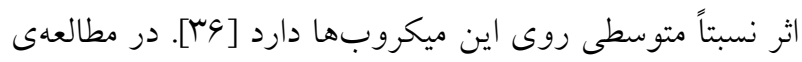

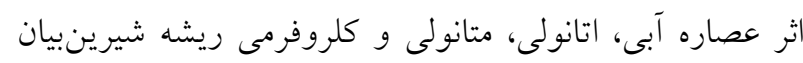

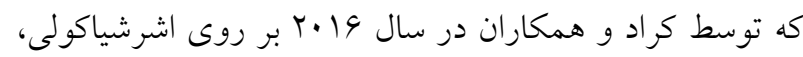

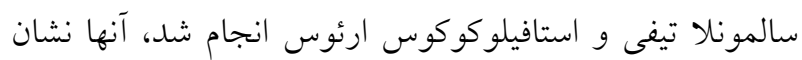

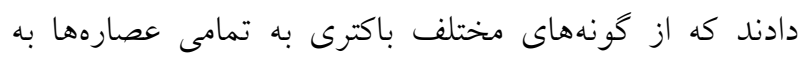

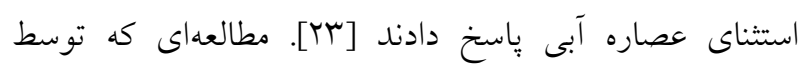

عصاره گياهان يكى از منابع بالقوه واجد تركيبات فنلى با

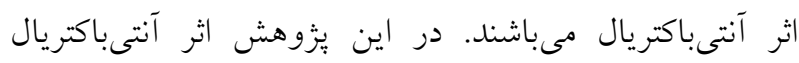

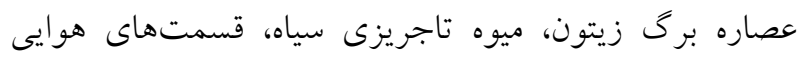

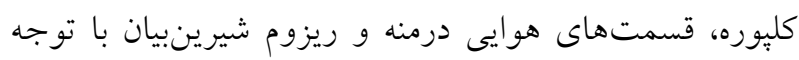

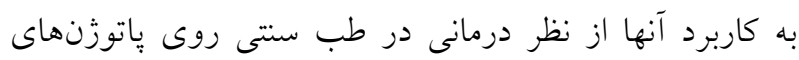

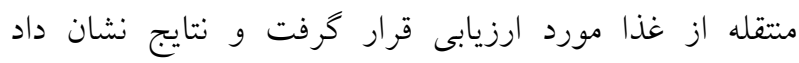
استافيلوكوكوس اورئوس حساسترين باكترى به عصارهها بوده

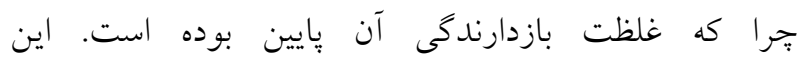

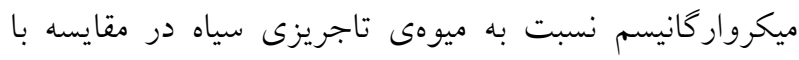

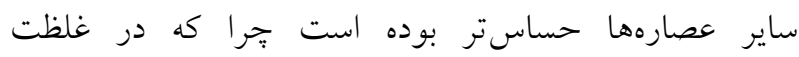

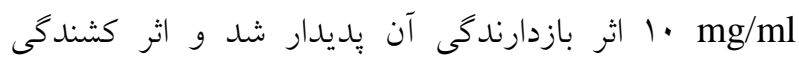

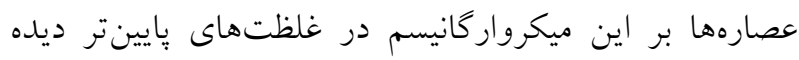

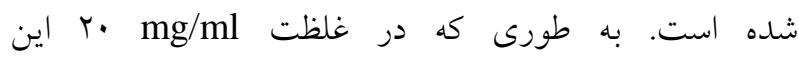
ميكرواركانيسم توسط عصارههاى ميوه تاجريزى سياه، كليوره

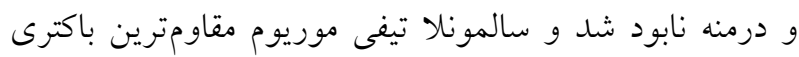

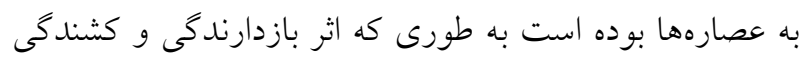

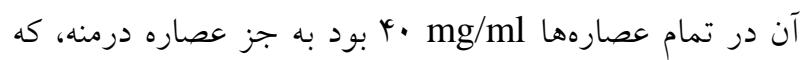

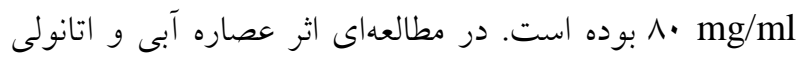

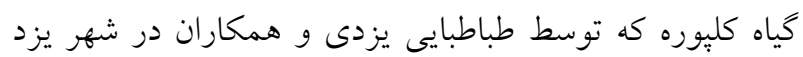

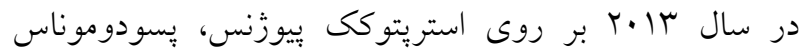

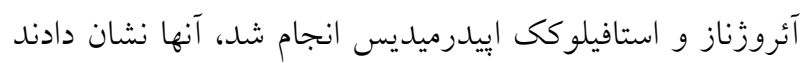


ينى سيلين بر روى استريتوكوى موتانس تفاوت معنىدارى

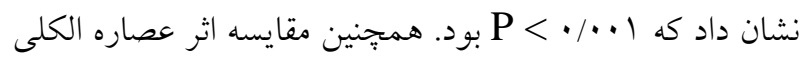

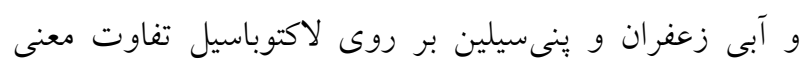

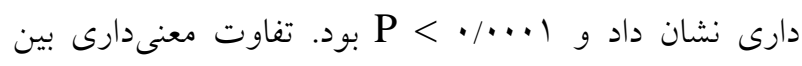

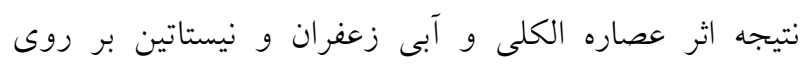

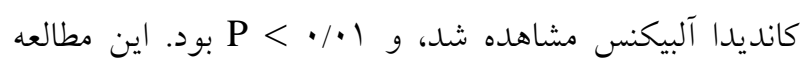

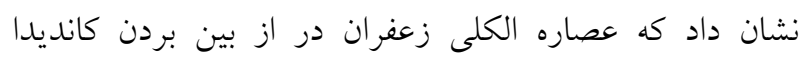

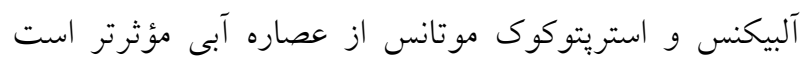

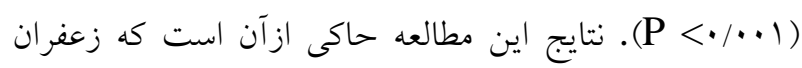

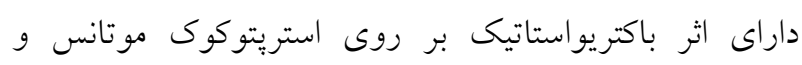

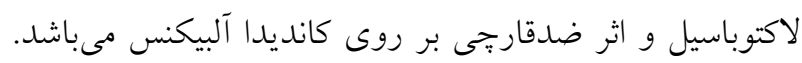

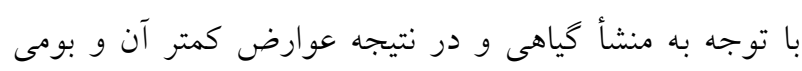

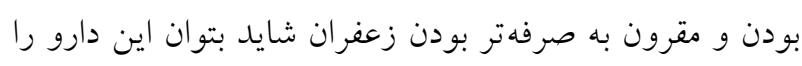

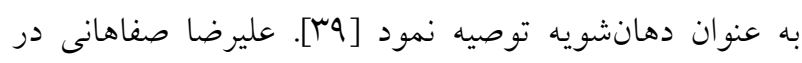

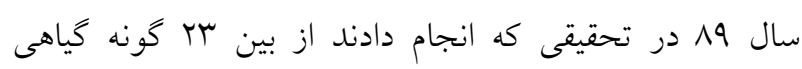

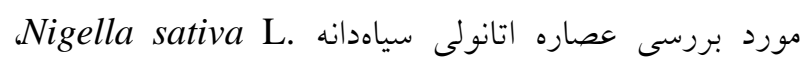
اكالييتوس Eucalyptus globulus Labill. ،Punica granatum L. أنار Hypericum perforatum L.

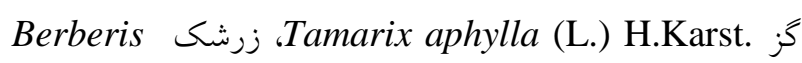

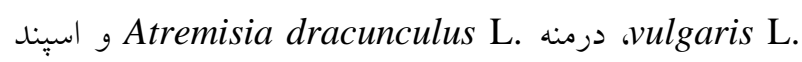
Peganum harmala L.

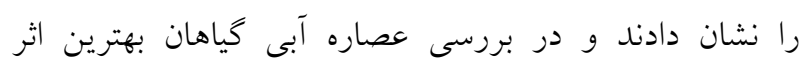

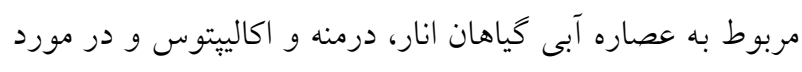

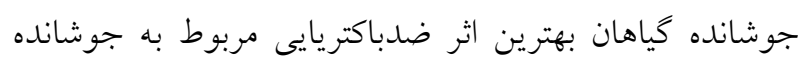

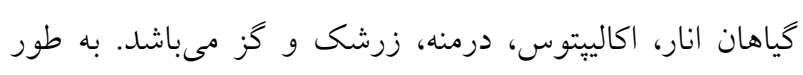

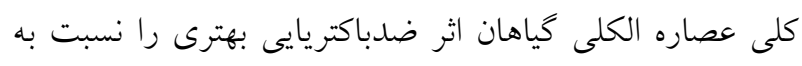

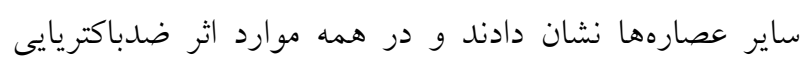

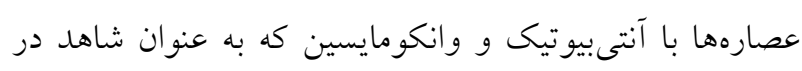

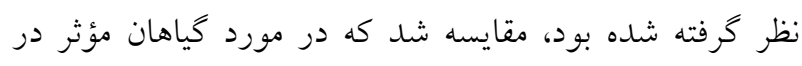

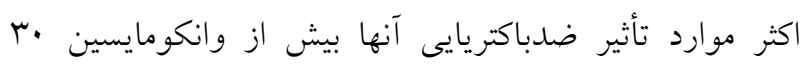

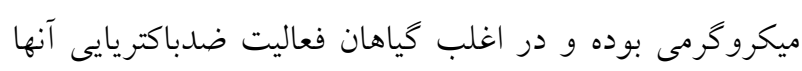

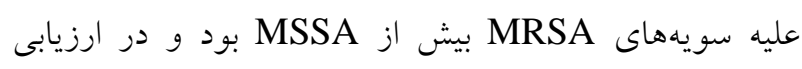

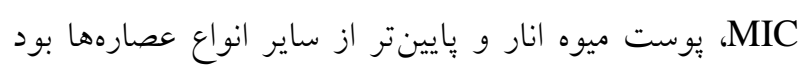
$[\mathrm{r} \cdot](\mathrm{MIC}=\cdot / \cdot 1 \mathrm{mg} / \mathrm{ml})$
صادقىنيا و همكاران در سال r. T به منظور تأثير عصاره

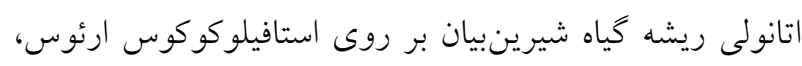

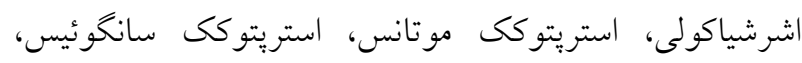

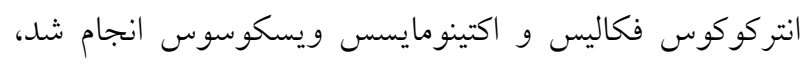

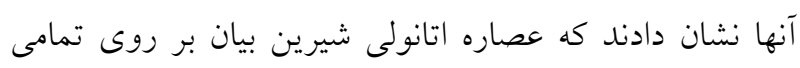

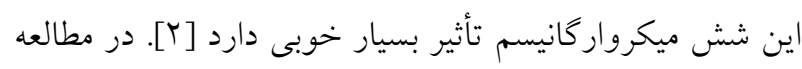

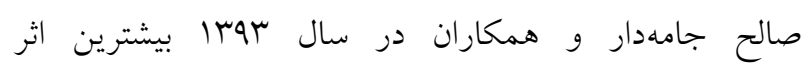

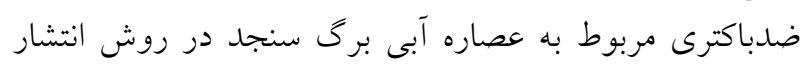

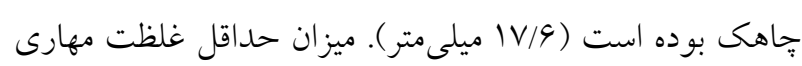

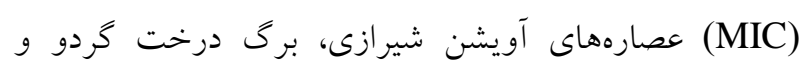

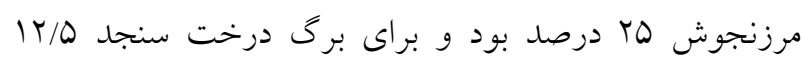

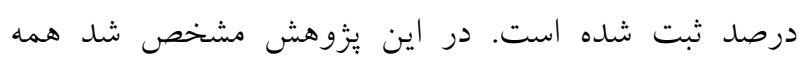

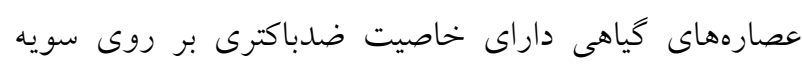

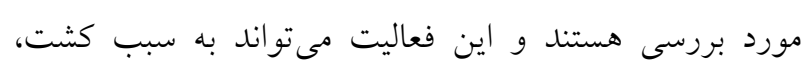

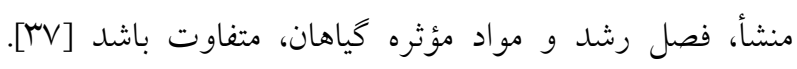

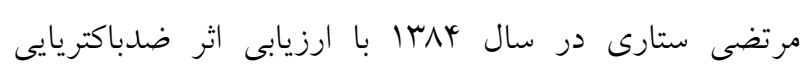
عصارههاى آبى و الكلى اكالييتوس بر سودوموناس آيروزينوزا

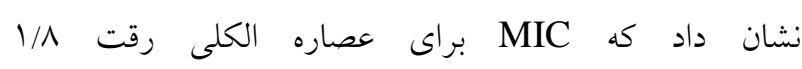

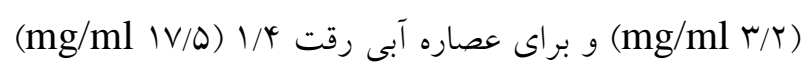

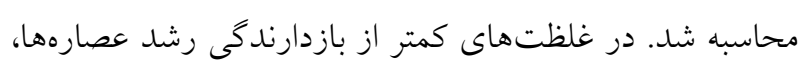

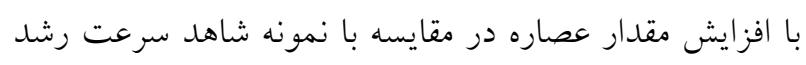

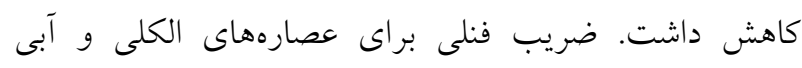

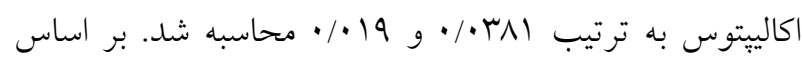

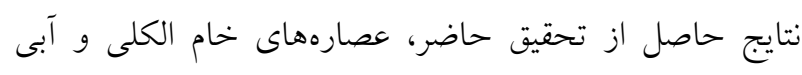

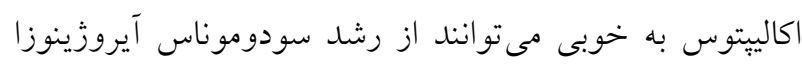

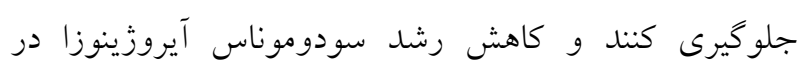

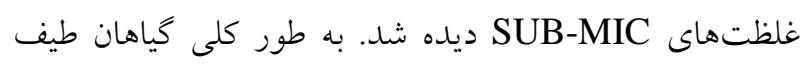

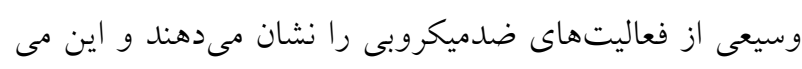

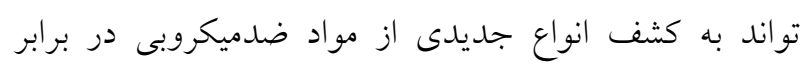

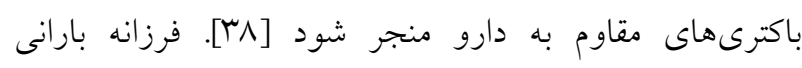
كرباسكى و همكاران در سال هو در مطالعهاى كه داشتند نشان فران

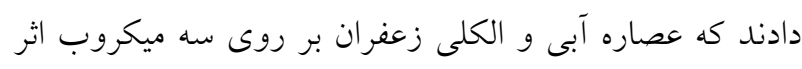

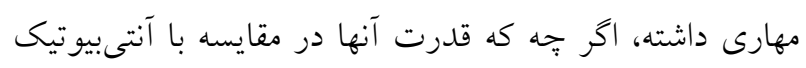

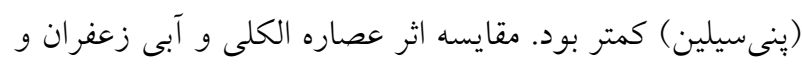




$$
\begin{aligned}
& \text { تشكر و قدردانى }
\end{aligned}
$$

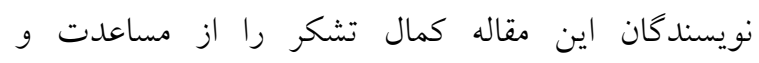

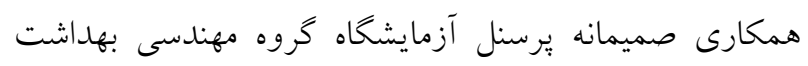

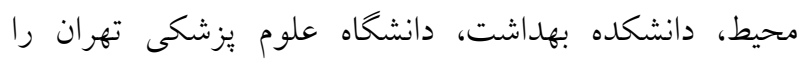

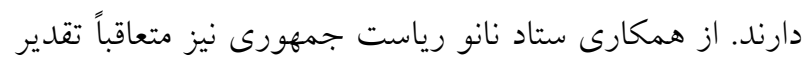

$$
\begin{aligned}
& \text { مىشود. }
\end{aligned}
$$

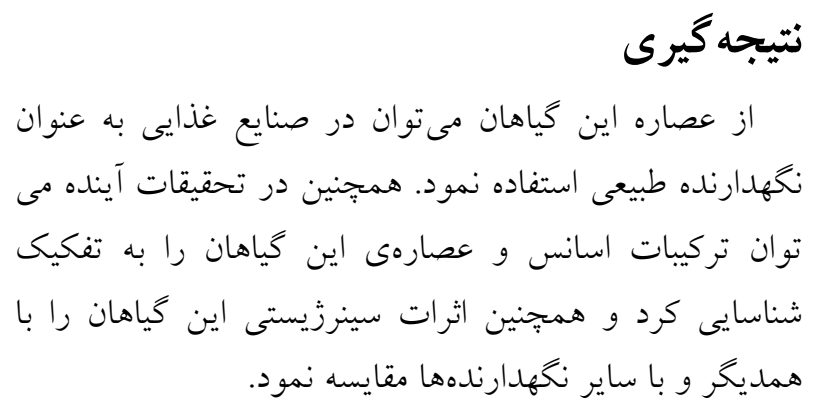

1. Abouhosseini Tabari M, Youssefi $M \quad R$, Moghaddas E, Ebrahimi M A, Nabavi Mousavi N and Naseri A. Antileashmanial activity of Artemisia sieberi essential oil against Leishmania infantum in vitro. Advanced Herbal Medicine 2016; 2 (2): 40 - 6.

2. Fereshteh Sedighinia A S A, Saman soleimanpour, Reza zarif, Javad Asili and Ghazvini K. Antibacterial activity of Glycyrrhiza glabra against oral pathogens: an in vitro study. AJP. 2012; 2 (3): 118 - 24.

3. Ahmadloo M, Shariatifar N, Mahmoudi R, Qajarbeygi P, Moazzen M, Akbarzadeh A, Nazmara $S$ and Dobaradaran S. Assessment of Polychlorinated Biphenyls Concentration in Egg Using GC-MS Method. JMUMS. 2019; 28 (168): $69-81$.

4. Gorji M E h, Ahmadkhaniha R, Moazzen M, Yunesian M, Azari A and Rastkari N. Polycyclic aromatic hydrocarbons in Iranian Kebabs. Food Control 2016; 60: 57 - 63.

5. Kiani A, Ahmadloo M, Shariatifar N, Moazzen M, Baghani A N, Khaniki G J, Taghinezhad A, Kouhpayeh A ,Khaneghah A M and Ghajarbeygi P. Method development for determination of migrated phthalate acid esters from polyethylene terephthalate (PET) packaging into traditional Iranian drinking beverage (Doogh) samples: a novel approach of MSPE-GC/MS technique. ESPR. 2018: 1 - 11.
6. Moazzen M, Khaneghah A M, Shariatifar N, Ahmadloo M, Eş I, Baghani A N, Yousefinejad S, Alimohammadi M, Azari A and Dobaradaran S. Multi-walled carbon nanotubes modified with iron oxide and silver nanoparticles (MWCNT$\mathrm{Fe} 3 \mathrm{O} 4 / \mathrm{Ag}$ ) as a novel adsorbent for determining PAEs in carbonated soft drinks using magnetic SPE-GC/MS method. Arabian Journal of Chemistry 2019; 12 (4): 476 - 88.

7. Moazzen M, Mahvi A H, Shariatifar N, Jahed Khaniki G, Nazmara S, Alimohammadi M, Ahmadkhaniha R, Rastkari N, Ahmadloo M and Akbarzadeh A. Determination of phthalate acid esters (PAEs) in carbonated soft drinks with MSPE/GC-MS method. Toxin Reviews 2018; 37 (4): $319-26$.

8. Abu-Shanab B, ADWAN G M, Abu-Safiya D, Jarrar $\mathrm{N}$ and Adwan K. Antibacterial activities of some plant extracts utilized in popular medicine in Palestine. Turkish J. Biology 2005; 28 (2 - 4): 99 102.

9. Arora P, Wani Z A, Nalli Y, Ali A and RiyazUl-Hassan S. Antimicrobial Potential of Thiodiketopiperazine Derivatives Produced by Phoma sp., an Endophyte of Glycyrrhiza glabra Linn. Microbial Ecol. 2016; 72 (4): 802 - 12.

10. Dar K, Bhat A, Amin S, Zargar M and Masood A. Evaluation of Antibacterial, Antifungal and Phytochemical Screening of Solanum nigrum. Biochem Anal Biochem 6: 309. doi: 10.4172/2161-

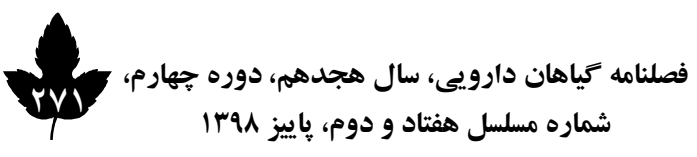


1009.1000309 Volume 6• Issue $1 \bullet 1000309$ Biochem Anal Biochem, an open access journal ISSN: 2161-1009 Page 2 of 6 drugs. It is estimated that there are about. 2017; 2.

11. Shariatifar N, Shoeibi S, Sani M J, Jamshidi A H, Zarei A, Mehdizade A and Dadgarnejad M. Study on diuretic activity of saffron (stigma of Crocus sativus L.) Aqueous extract in rat. JAPTR. 2014; 5 (1): 17.

12. Thielmann J, Kohnen $S$ and Hauser $C$. Antimicrobial activity of Olea europaea Linné extracts and their applicability as natural food preservative agents. International Journal of Food Microbiol. 2017; 251: 48 - 66.

13. Yazdi $F \mathrm{~T}$ and Behbahani B A. Antimicrobial effect of the aqueous and ethanolic Teucrium polium L. extracts on gram positive and gram negative bacteria "in vitro". JPS. 2013; 4 (4): 55 - 61.

14. Zendehdel $M$, Fallah $R$, Baghbanzadeh A, Pourrahimi M, Shariatifar $N$ and Garavand S. Effect of intracerebroventricular injection of aqueous extract and essential oil of Pulicaria gnaphalodes on PTZ-induced seizures in male rat. Physiology and Pharmacol. 2013; 17 (1): 94 - 100.

15. Gandomi H, Abbaszadeh S, Rahimikia E and Shariatifar N. Volatile Organic Compound from Pulicaria gnaphalodes and the Antibacterial and Antifungal Properties of Its Essential Oil and Aqueous, Ethanolic and Methanolic Extracts. $J$. Food Processing and Preservation 2015; 39 (6): 2129 - 34.

16. Gandomi Nasrabadi H, Azami Sarokelaei L, Misaghi A, Abbaszadeh S, Shariatifar N and Tayyar Hashtjin N. Antibacterial effect of aqueous and alcoholic extracts from petal of saffron (Crocus sativus L.) on some foodborne bacterial pathogens. JMP. 2012; 2 (42): 189 - 96.

17. Talaei Gh R and Delfan B. A study on the antibactrial effect of extracts of Annona seneglaensis, Chrysanthemum, Rhus coriria on a number of gram positive and negative bacteria. Herbal Medicines J. 2013; 3 (3): 19 - 23.
18. Hosein motamedi $\mathrm{s} \mathrm{m} \mathrm{s} \mathrm{n}$, esmaeil darabpour. A study on the antibactrial effects of ethanolic and methanolic extracts of Saffron (Crocus sativus L.) on some food borne pathogens. J. Food Microbiol. 2016; 2 (4): 15 - 27.

19. Kamkar A, Ardekani M R S, Shariatifar N, Misagi A, Nejad A S M and Jamshidi A H. Antioxidative effect of Iranian Pulicaria gnaphalodes L. extracts in soybean oil. South African Journal of Botany. 2013; 85: 39 - 43.

20. Shariatifar N, Rezaei M, Sayadi M, Moshafi M, Saeedi M, Mohammadhosseini N, Moghimi S and Foroumadi A. In-vitro antibacterial evaluation of some fluoroquinolone derivatives against food borne bacteria. J. Sci. I. R. Iran. 2016; 27 (2): 129 - 33.

21. Sudjana A N, D’Orazio C, Ryan V, Rasool N, $\mathrm{Ng} \mathrm{J}$, Islam $\mathrm{N}$, Riley $\mathrm{T} \mathrm{V}$ and Hammer $\mathrm{K}$ A. Antimicrobial activity of commercial Olea europaea (olive) leaf extract. International $J$. Antimicrobial Agents 2009; 33 (5): 461 - 3.

22. Kamkar A, Tooryan F, Basti A, Misaghi A and Shariatifar N. Chemical composition of summer savory (Satureja hortensis L.) essential oil and comparison of antioxidant activity with aqueous and alcoholic extracts. Journal of Veterinary Research. 2013; 68 (2): 183 - 90.

23. Lokesh Kirad S S. In-vitro Antibacterial Activity of Licorice Root on Food-Borne Pathogens. IJRMBS. 2016; 2 (5): 30 - 40.

24. Malki S, Abidi L, Hioun $S$ and Yahia A. Variability of phenolic contents in ethanolic extracts of Teucrium polium L. populations and effect on antioxidant and antimicrobial activities. $J$. Microbiology and Biotechnology Res. 2017; 5 (4): $21-7$.

25. Modi V, Mahendrakar N, Sachindra N and Rao D N. Quality of nuggets prepared from fresh and smoked spent layer chicken meat. J. Muscle Foods 2004; 15 (3): 195 - 204.

26. Mohammadzadeh Moghaddam M, Elhamirad A, Shariatifar N, Saidee Asl M and Armin M. Anti-bacterial effects of essential oil of Cardaria 
draba against bacterial food borne pathogens. The Horizon of Medical Sciences. 2014; 19 (5): 9 - 16.

27. Naz S, Jabeen S, Ilyas S, Manzoor F, Aslam F and Ali A. Antibacterial activity of Curcuma longa varieties against different strains of bacteria. Pak. J. Bot. 2010; 42 (1): 455 - 62.

28. Pereira A P, Ferreira I C, Marcelino F, Valentão P, Andrade P B, Seabra R, Estevinho L, Bento A and Pereira JA. Phenolic compounds and antimicrobial activity of olive (Olea europaea L. Cv. Cobrançosa) leaves. Molecules 2007; 12 (5): $1153-62$.

29. Sedighinia F, Safipour Afshar A, Asili J and Ghazvini K. Antibacterial activity of Glycyrrhiza glabra against oral pathogens: an in vitro study. AJP. 2012; 2 (3): 118 - 24.

30. )Kouhpayeh A, Moazzen M, Jahed Khaniki G R, Dobaradaran S, Shariatifar N, Ahmadloo M ,Azari A, Nazmara S, Kiani A and Salari M. Extraction and Determination of Phthalate Esters (PAEs) in Doogh. JMUMS. 2017; 26 (145): 257 - 67.

31. Seyyednejad S, Maleki S, Damabi N M and Motamedi H. Antibacterial activity of Prunus mahaleb and Parsley (Petroselinum crispum) against some pathogen. Asian. J. Biol. Sci. 2008; 1: $51-5$.

32. Shahba S, Bokaeian M, Mozafari-Sabet N A, Saeidpour-Parizi A, Bameri $Z$ and Nikbin $M$. Antibacterial effect of Teucrium polium on the bacteria causing urinary tract infections. Zahedan $J$. Research in Medical Sciences 2014; 16 (3): 44 - 9.

33. Shariatifar N, Jahed G R, Tooryan F and Rezaei M. Stabilization of Soybean oil by Rosmarinus officinalis L. extracts during accelerated storage. International J. PharmTech Research. 2014; 6 (5): 1724 - 1730.

34. Shariatifar N, Kamkar A, Shamse Ardekani M
R, Misagi A, Akhonzade A and Jamshidi AH. Composition and antioxidant activities of Iranian Pulicaria gnaphalodes essential oil in Soybean oil. PJPS. 2014; 27 (4): 807 - 812.

35. Shariatifar N, Rahimnia R, Jamshidi A, Pirali Hamedani $M$ and Shoeibi S. Effect of Ethanolic Extract of Mespilus germanica on Cutaneous Leishmaniasis in BALB/c Mice. JMP. 3 (39): 76-81.

36. Zubair M, Rizwan K, Rasool N, Afshan N, Shahid M and Ahmed V U. Antimicrobial potential of various extract and fractions of leaves of Solanum nigrum. International J. Phytomedicine 2011; 3 (1): 63.

37. Jamehdor S, Zarabi M, Mehrnejad F and Yavar poor kordestani V. In vitro Evaluation of antibacterial efficacy of aqueous extracts of Iranian Native Plants on the Standard Strains of Pseudomonas aeruginosa (Short Communication). Iranian Journal of Medical Microbiol. 2014; 8 (2): 51 - 4.

38. Sattari M, Shahbazi N and Najar Peeryeh S. An assessment of antibacterial effect of alcoholic and aquatic extracts of Eucalyptus leaves on Pseudomonas aeruginosa. Pathobiology Res. 2006; 8 (1): 19 - 23.

39. Barani Karbasaki F, Hossenzadeh (H, Fazli Bazzaz B S, Hoda V, Ghazvini K and Ajami B - a $\mathrm{m}$. Evaluation of Antimicrobial effects of Aqueous and Alcoholic Extracts of Saffron on Oral Pathogenic Microbes (Streptococcus Mutans, Lactobacillus, Candida Albicans). J. Mashhad Dental School 2016; 40 (3): 203 - 12.

40. Safahani A, Ataie M, Rabie M, Dadgar T and Ghaemi E. Comparison of antibacterial activity of some of the medical plants extracts of Golestan province against Staphylococcus aureus. JHD. 2011; 1 (4): 41 - 51.

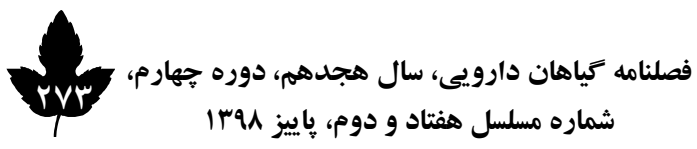




\title{
Study of the Antimicrobial Effects of Aqueous Extract of Olea europaea, Solanum nigrum, Artemisia sieberi, Teucrium polium, Glycyrrhiza glabra on some Food-borne Pathogenic Bacteria
}

\author{
Shariatifar N (Ph.D.) ${ }^{1,2,3}$, Pirali-Hamedani M (Ph.D. Student) ${ }^{4}$, Moazzen M (M.Sc.) ${ }^{1}$, \\ Ahmadloo M (M.Sc.) ${ }^{5}$, Yazdani D (Ph.D.) ${ }^{6}$ \\ 1- Department of Environmental Health Engineering, School of Public Health, Tehran \\ University of Medical Sciences, Tehran, Iran \\ 2- Halal Research Center of IRI, FDA, Tehran, Iran \\ 3- Food safety Research Center, Shahid Beheshti University of Medical Science, Tehran, \\ Iran \\ 4- School of Pharmacy, Tehran University of Medical Sciences, Tehran, Iran \\ 5- Department of Public Health, School of public Health, Qazvin University of Medical \\ Sciences, Qazvin, Iran \\ 6- Medicinal Plants Research Center, Institute of Medicinal Plants, ACECR, Karaj, Iran \\ *Corresponding author: School of Pharmacy, Tehran University of Medical Sciences, \\ Tehran, Iran \\ Tel: $+98-21-64120$ \\ Email: piraliha@tums.ac.ir
}

\section{Abstract}

Background: The aqueous extract of some plants has an antibacterial effect on pathogenic bacteria for humans.

Objective: This study designed to investigate the antimicrobial activity of aqueous extract of some plants on some food-borne pathogenic bacteria in a laboratory setting has done.

Method: In an experimental study, plants collected from of Tehran city and aqueous extract of them, extracted. To determine the minimum inhibitory concentration (MIC) and minimum bactericidal concentration (MBC) with two ways of visual and turbidity (OD), serially different concentrations $(1.25-80 \mathrm{mg} / \mathrm{ml})$ on different cultures was prepared. Disc diffusion (DD) test in concentrations of 10, 20 and $40 \mathrm{mg} / \mathrm{ml}$ to determine the average diameter of inhibition for some bactria, done.

Results: The results showed that the inhibitory and fungicidal aqueous extract of Solanum americanum on various bacteria was more than any other aqueous extracts (Staphylococcus aureus MIC $=10 \mathrm{mg} / \mathrm{ml}$ ) and also Staphylococcus aureus and Salmonella typhimurium were the most sensitive and most resistant bacteria to aqueous extract, respectively.

Conclusion: According to the results, we can be hopeful the extract of Solanum americanum in the treatment of pathogenic bacteria such as S. aureus, can be help and it can used in the food industry as a food protection. Recommended by extracting the active ingredients of the extract of this plant and other plants, more research done on the composition of extract.

Keywords: Antimicrobial effects, Aqueous extraction, Food-borne diseases, Minimum bactericidal concentration (MBC), Minimum inhibitory concentration (MIC) 